\title{
Exploring the Design of a Social Learning Platform for Supporting Users' E-Teaching Skill Development
}

\author{
Haiming Liu \\ University of Bedfordshire, \\ Luton, LU1 3JU, UK \\ Haiming.liu@beds.ac.uk
}

\author{
Elizabeth J Hartnett \\ The Open University, \\ Milton Keynes, MK7 6AA, UK \\ eliz.hartnett@open.ac.uk
}

\begin{abstract}
A good e-learning experience is important for users' effective open learning on Massive Open Online Courses (MOOCs), requiring useful learning technologies and good eteaching skills. In this paper, an early release of an online social learning platform that allows doctoral students to develop open online courses and practice their e-teaching skills, is evaluated, in order to explore design for such tasks. The evaluation shows that a well-designed social learning platform can enrich users' teaching and learning. However, other factors such as users' digital literacy need to be considered and supported by the technologies during the design, in order to improve the open learning experiences for both students and the tutors.
\end{abstract}

Keywords - e-learning, e-teaching, social learning

\section{INTRODUCTION}

A university that provides open and distance learning, has a cross-university project to create a Web 2.0 online learning platform called SocialLearn (SL) that aims to provide postdoctoral students' online teaching experiences. The SL platform allows social interaction and encourages learning by making it easy for teachers to create MOOCs [1] and to lead learners through the digital MOOC resources. In competition with $\mathrm{PhD}$ students from other universities, $\mathrm{PhD}$ students expect teaching opportunities in order to develop their teaching skills. Thus, the SL platform becomes an opportunity to trial provision of e-learning in Higher Education (HE) and to practice preparation of online teaching materials. This paper introduces the SL platform, reports the findings and insights from a user study and suggests some design improvements.

\section{SOCIALLEARN}

This section presents how the Web2.0 online social learning platform was designed based on pedagogy of online social learning [2-4], online learning networks [5-6] and design invention from designer's experience of using social design invention networking sites, such as Facebook ${ }^{1}$, LinkedIn $^{2}$ and Google $+^{3}$, etc.

Current learning management systems (LMS) are virtual classrooms [1]. The greatest opportunities that Web2.0 affords are within social and situated learning [2] because they focus on learning as social and participative situated learning [3], which is important for practice and development of skills, including teaching skills. Weller [1] suggests that online learning spaces might be used to encourage socially constructed learning.

A platform is needed to support social learning in context by providing feedback and social rewards on performance in peer groups. However, Vassileva [7] assumes that students are digital natives, used to communicating constantly through text on Twitter or Facebook, whereas Bennett et al [4] argue that some students are not so easily attuned to social networking, in which case, the implications for design differ. The SL affords social interaction for learning by using structured paths through learning resources (learning paths) (Figure 1) and its associated groups. Teaching material provided opportunities for peer discussion $[5,6]$, so each step of every path included a discussion area, similar to MOOCs but internal, informal and small scale.

\section{USER STUDY}

The aim of the study was to evaluate the effectiveness and the usability of the SL platform for the PhD students' eteaching skill development in an effort to explore an effective design for the social learning platform to support e-teaching.

Eight doctoral students from four faculties participated in the study. Webb and Renshaw in [7] suggest five or six participants for an eye-tracking study and Nielsen [8] says eight is typical for usability testing. Participants attended a face-to-face introduction to teaching in higher education (HE), a demonstration of the SL functions and a hands-on session to produce their own teaching material. After the workshop,

\footnotetext{
${ }^{1} \mathrm{http}: / /$ www.facebook.com/

${ }^{2} \mathrm{http}: / /$ www.linkedin.com/home

${ }^{3}$ https://plus.google.com/
} 
participants undertook a 12-hour online study package on teaching in HE on SL, followed up through written feedback on SL and a final interview with the participants. A qualitative analysis was applied to screen captures, logging data, written comments and the interview transcripts.

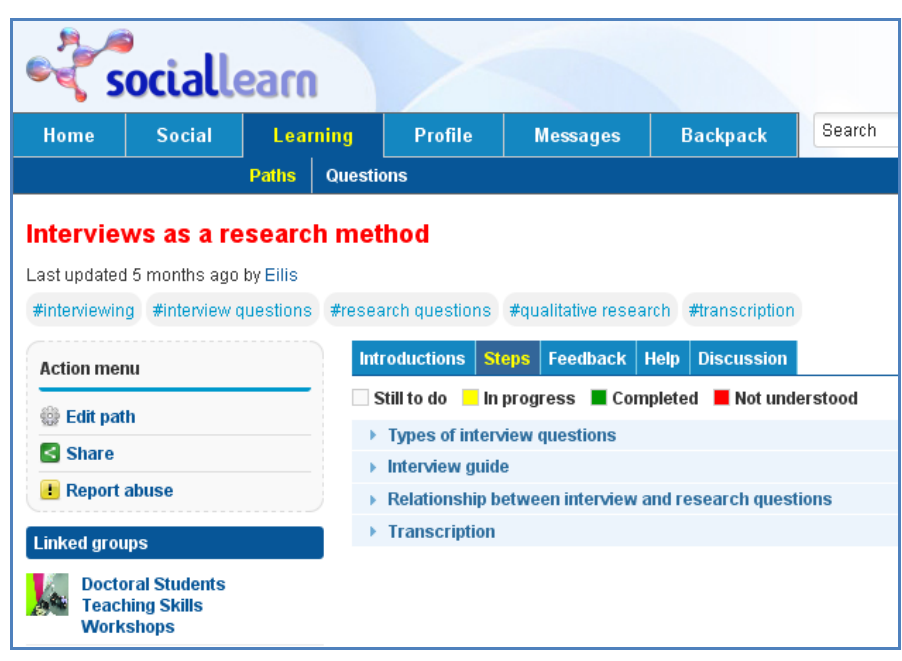

Figure 1: Learning Path

\section{USER STUDY RESULTS AND DISCUSSION}

SL provided doctoral students with a digital experience of teaching that few other universities provide. The participants thought SL a useful online social learning platform that could support their learning to teach. For example, "SL enabled me to develop my teaching skills when I have no opportunity to access students in person." "I am pleased to know that there is other ways to develop my teaching/e-teaching skills without teaching students in the class room." "The experience to teach on SL made me think about teaching from a completed different perspective."

Users found it easy to design and create learning paths, and practiced setting up material in their doctoral specialism. Four of the participants completed such paths.

The participants could find their way around the platform. However, they some-times struggled to grasp how to make the best use of the functions. For example, "There are too many places for publishing a post,... etc..... It's confusing which one I should use." "I clicked on a link provided in a path step, but now I don't know how to get back to where I was." "How do I find the learning path again that I have just viewed?" Improved navigation support is needed with fewer pages; duplicated functions should be removed.

Visibility of feedback was poor. For example, "I clicked on 'attend' to reply to an event invitation, but I could not see any confirmation, so I clicked the "attend" button a few times, and then concluded that the function was not working." Logging data and screen capture show a small notification above the event's name that appeared for ten seconds. Hence, the visibility of the notification needs improvement. The users expect the notification to be visible and in the right place.
Users' digital literacy proved a key challenge, which is an important finding from the study. None of the doctoral students had used the SL platform and some had not used other social learning platforms such as Facebook or LinkedIn. One participant could not find his way through the material, making no attempt to search. As the users have different levels of digital literacy skills, the design of the SL platform should be personalized for different user groups, that is, right for the particular learner [7] matching learning techniques to widgets[8].

The findings show that the users can be grouped into different groups based on their digital literacy levels. A design that reflects the differences for different user groups will improve the users' overall learning and teaching experiences. The personalized design will engage the users more to the eteaching and encourage the users to develop more effective learning materials.

\section{CONCLUSION}

The SL platform is developed for supporting users' online social learning especially for MOOC learners. It is important to ensure the effectiveness of the platform for the users' teaching and learning. In the user study, the SL platform is employed to be a learning to teach tool for a group of $\mathrm{PhD}$ students to develop their e-teaching experiences. The findings show that the SL platform offers opportunities and support for training to teach, but because of design limitations, some of the users do not persist in developing new material so that learning opportunities are lost. This user case study also identifies the importance of the users' digital literacy level and users' different preferences. A more personalised platform is needed to support different users' needs. More user studies would develop user models based on digital literacy levels and preferences to enhance the design of the platform and provide personalised experiences. Finally, we suggest further research on training $\mathrm{HE}$ teachers to develop e-learning courses especially on social learning platforms.

\section{REFERENCES}

[1] Weller, M. (2009) Using learning environments as a metaphor for educational change. On the Horizon, 17, 3 , 181 - 189.

[2] Conole, G. (2008) New Schemas for Mapping Pedagogies and Technologies. Ariadne 56.

[3] Lave, J. and Wenger, E. (1991) Situated learning: legitimate peripheral participation. Cambridge University Press, Cambridge.

[4] Bennett, S., Maton, K. and Kervin, L. (2008) The 'digital natives' debate: A critical review of the evidence. British Journal of Educational Technology, 39, 5, 775-786.

[5] Boud, D. and Lee, A. (2005) "Peer learning" as pedagogic discourse for research education. Studies in Higher Education, 30, 5, 501-516.

[6] Topping, K. J. (2005) Trends in peer learning. Educational Psychology Review, 25, 6, 631-645 (625th anniversary edition).

[7] Vassileva, J. (2008) Toward Social Learning Environments. IEEE Transactions on Learning Technologies, 1, 4, 199-214.

[8] Berthold, M., Lachmann, P., Nussbaumer, A., Pachtchenko, S., Kiefel, A. and Albert, D. (2012) Psycho-pedagogical mash-up design for personalising the learning environment. In Proceedings of the Proceedings of the 19th international conference on Advances in User Modeling, Girona, Spain. 